\title{
Determination of Gamma-ray Attenuation Coefficients at Different Energies in Amasya Marbles
}

\author{
B. MAVI ${ }^{a, *}$, F. ONER ${ }^{b}$ AND I. AKKURT ${ }^{c}$ \\ ${ }^{a}$ Amasya University, Physics Department, Amasya, Turkey \\ ${ }^{b}$ Amasya University, Computer Education and Instructional Technology Department, Amasya, Turkey \\ ${ }^{c}$ Süleyman Demirel University, Physics Department, Isparta, Turkey
}

\begin{abstract}
The linear attenuation coefficients of different marble samples (Perlato Beige, Regal Beige and Crema Siva Beige) produced in Amasya were measured. The measurements have been performed at the photon energies of 511,835 and $1274 \mathrm{keV}$ which were obtained using ${ }^{22} \mathrm{Na}$ and ${ }^{54} \mathrm{Mn}$ sources. The measurements have been performed using a gamma spectrometer which contains $3^{\prime \prime} \times 3^{\prime \prime} \mathrm{NaI}(\mathrm{Tl})$ detector connected to 16384 channel Multi-ChannelAnalyser (MCA).
\end{abstract}

DOI: 10.12693/APhysPolA.128.B-395

PACS: 28.41.Qb, 07.85.Nc

\section{Introduction}

With the development of technology, human body has been exposed to extra radioactivity in addition to the natural radioactivity. There are three methods for protecting from radiation- time, distance and shielding. Shielding is the most important method in which shielding materials becomes important. The literature is rich in works dealing with linear attenuation coefficients of construction materials [1-5] Marble is an important material to be used in building construction. In this study, the linear attenuation coefficients of three different types of marble have been measured at three different photon energies.

\section{Materials and methods}

The linear attenuation coefficients of marble samples were measured using the gamma spectrometer, contains a Canberra type $3^{\prime \prime} \times 3^{\prime \prime} \mathrm{NaI}(\mathrm{Tl})$ detector. The communication of the system was performed using Genie2000 software [6-8].

The linear attenuation coefficients have been evaluated comparing $\mathrm{N}$ and $\mathrm{N}_{0}$, which are the measured count rates in detector, with and without the absorber, respectively.

$$
N=N_{0} \mathrm{e}^{-\mu x},
$$

where $N$ is the number of counts recorded in the detector attenuation; $N_{0}$ the the number of counts recorded in the detector before attenuation; $\mu$ is the linear attenuation coefficient; $x$ is the thickness of the marble samples.

\section{Results and discussion}

The measured linear attenuation coefficient $(\mu)$ for the all Amasya marble samples have been obtained for 511, 825 and $1274 \mathrm{keV}$ gamma rays and the results have been displayed in Fig. 1 as a function of gamma ray energy.

\footnotetext{
*corresponding author; e-mail: fbmavi32@hotmail.com
}

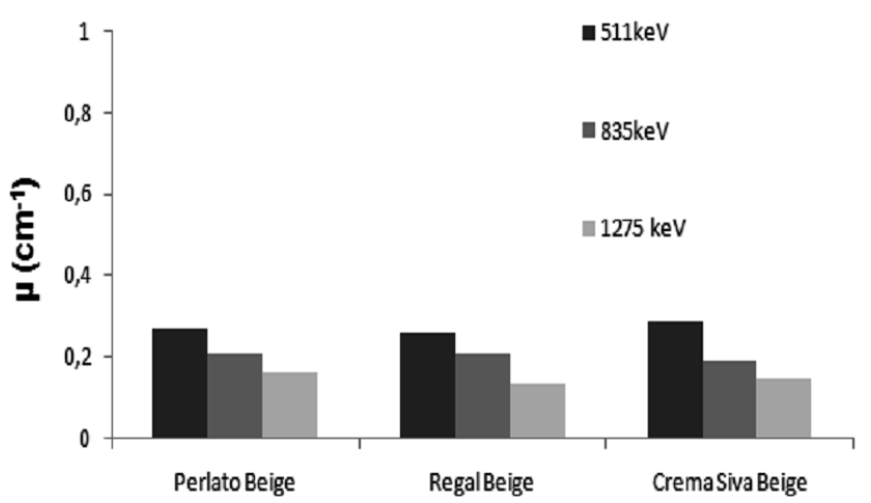

Fig. 1. The measured $\mu$ for Amasya marble energies at $511,835,1275 \mathrm{keV}$.

It can be seen from this figure that the linear attenuation coefficients decreased with the increasing gamma ray energy. The linear correlation between photon energies and linear attenuation coefficients have been seen for all Amasya marble sample and $R^{2}$ was found over 0.90 is shown in Fig. 2.

The effectiveness of gamma-ray shielding is described in terms of the half value layer (HVL) or the tenth value layer (TVL) of a material. HVL is the thicknesses of an absorber that will reduce the radiation to half, and the TVL is the thicknesses of an absorber that will reduce the $\gamma$-radiation to tenth of its intensity $[1,2,9]$.

HVL and TVL, the linear attenuation coefficients were concluded using the following Eq. (2):

$$
x_{\frac{1}{2}}=\frac{\ln 2}{\mu}, \quad x_{\frac{1}{10}}=\frac{\ln 10}{\mu} .
$$

The transmission rate of the marble as a function of material's thickness has been displayed in Fig. 3. It can be seen from this figure that larger thickness of materials is needed to stop higher energy photons. 


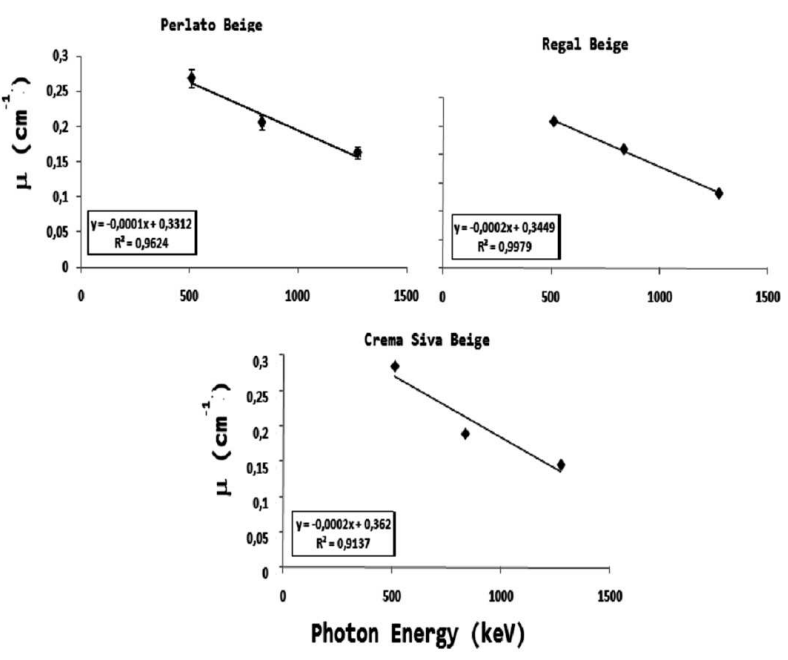

Fig. 2. The variation of the linear attenuation coefficients with the different energy.

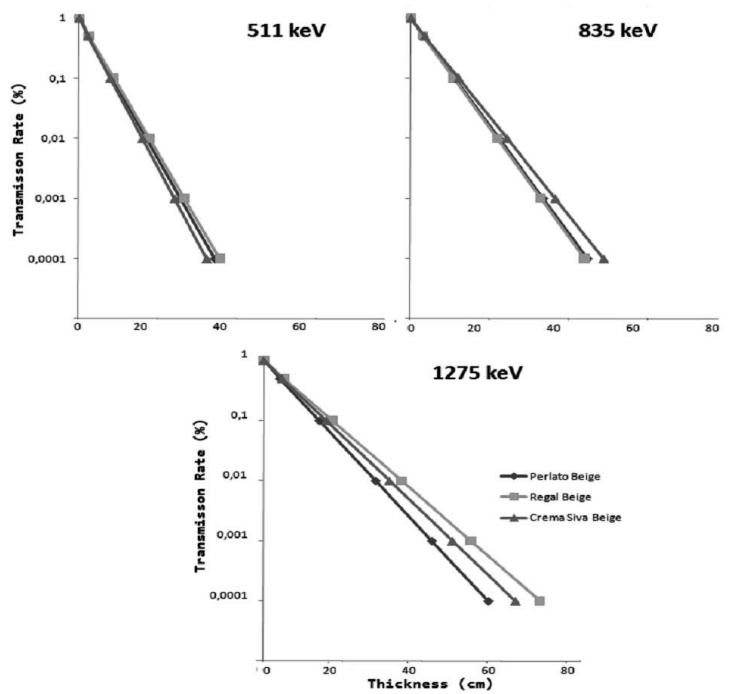

Fig. 3. Transmission rate of the Amasya marbles for ${ }^{54} \mathrm{Mn}$ and ${ }^{22} \mathrm{Na}$.

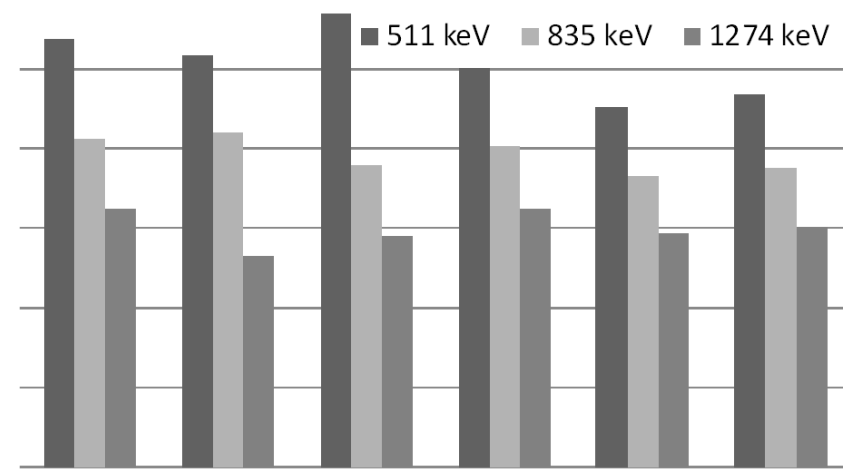

Fig. 4. The linear attenuation coefficients compared with measurement and calculation.
The measurement of the linear attenuation coefficients $(\mu)$ of Amasya marbles were compared with the calculated for basalt, andesite and limra. The linear attenuation coefficients for basalt, andesite and limra were calculated at photon energies of $1 \mathrm{keV}-100 \mathrm{GeV}$ and measured at photon energies of 511, 825 and $1274 \mathrm{keV}$. It has been evaluated with the mass attenuation coefficients $(\mu / \rho)$ which were obtained using XCOM computer code.

In order to test samples it is compare with the standard building materials such as basalt, andesite and limra and displayed in Fig. 4. It is shown that in Fig. 4 where the linear attenuation coefficients comparison of measured Amasya marble samples and calculated some building materials linear attenuation coefficients as a function of energy.

It can be concluded from this work that the Amasya marble samples are commonly used construction material and the samples are more suitable than basalt, andezite and limra for the building construction in terms of radiation shielding materials.

\section{Acknowledgments}

The authors thanks the Amasya Marble samples provided by Fimar Holding.

\section{References}

[1] B. Mavi, Ann. Nucl. En. 44, 22 (2012).

[2] I. Akkurt, S. Kilincarslan, C. Basyigit, B. Mavi, H. Akyildirim, Int. J. Phys. Sci. 4, 588 (2009).

[3] M.E. Medhat, Ann. Nucl. En. 36, 849 (2009).

[4] M.I. Awadallah, M.M.A. Imran, J. Environ. Rad. 94, 129 (2007).

[5] S.C. Charanjeet, T. Singh, A. Kumar, G.S. Mudahar, Ann. Nucl. En. 31, 1199 (2004).

[6] Genie 2000, (3.0), 2004, Operation Manual, Canberra Industries.

[7] I. Akkurt, B. Mavi, H. Akyildirim, S. Kilincarslan, C. Basyigit, AIP Conf. Proc. 899, 533 (2007).

[8] B. Mavi, I. Akkurt, Radiat. Phys. Chem. 79933 (2010).

[9] I. Akkurt, H. Akyıldırım, B. Mavi, S. Kilincarslan, C. Basyigit, Rad. Meas. 45, 827 (2010). 